\title{
The relationship of perceptions of tap water safety with intake of sugar-sweetened beverages and plain water among US adults
}

\author{
Stephen J Onufrak ${ }^{1, *}$, Sohyun Park ${ }^{1}$, Joseph R Sharkey ${ }^{2}$ and Bettylou Sherry ${ }^{1}$ \\ ${ }^{1}$ Centers for Disease Control and Prevention, Division of Nutrition, Physical Activity and Obesity, Obesity \\ Prevention and Control Branch, 4770 Buford Highway NE, MS K-26, Atlanta, GA 30341, USA: \\ ${ }^{2}$ Texas A\&M University, School of Rural Public Health, College Station, TX, USA
}

Submitted 23 December 2011: Final revision received 29 June 2012: Accepted 24 August 2012: First published online 260 0ctober 2012

\begin{abstract}
Objective: Research is limited on whether mistrust of tap water discourages plain water intake and leads to a greater intake of sugar-sweetened beverages (SSB). The objective of the present study was to examine demographic differences in perceptions of tap water safety and determine if these perceptions are associated with intake of SSB and plain water.

Design: The study examined perceptions of tap water safety and their cross-sectional association with intake of SSB and plain water. Racial/ethnic differences in the associations of tap water perceptions with SSB and plain water intake were also examined. Setting: Nationally weighted data from the 2010 HealthStyles Survey ( $n$ 4184).

Subjects: US adults aged $\geq 18$ years.

Results: Overall, $13 \cdot 0 \%$ of participants disagreed that their local tap water was safe to drink and $26.4 \%$ of participants agreed that bottled water was safer than tap water. Both mistrust of tap water safety and favouring bottled water differed by region, age, race/ethnicity, income and education. The associations of tap water mistrust with intake of SSB and plain water were modified by race/ethnicity $(P<0 \cdot 05)$. Non-white racial/ethnic groups who disagreed that their local tap water was safe to drink were more likely to report low intake of plain water. The odds of consuming $\geq 1 \mathrm{SSB} / \mathrm{d}$ among Hispanics who mistrusted their local tap water was twice that of Hispanics who did not $(\mathrm{OR}=2 \cdot 0 ; 95 \%$ CI $1 \cdot 2,3 \cdot 3)$.

Conclusions: Public health efforts to promote healthy beverages should recognize the potential impact of tap water perceptions on water and SSB intake among minority populations.
\end{abstract}

At present, approximately half of adults in the USA consume sugar-sweetened beverages (SSB) $\uparrow$ on any given day $^{(1)}$ and SSB intake is higher among Mexican Americans and blacks than among non-Hispanic whites ${ }^{(1)}$. Consumption of SSB has been associated with adverse health consequences including obesity ${ }^{(2,3)}$, poor mental health ${ }^{(4)}$ and type 2 diabetes ${ }^{(5)}$. Increasing intake of plain drinking water has been recommended by the Institute of Medicine to prevent dehydration and suggested as a means to prevent weight gain by reducing energy intake through displacement of $\mathrm{SSB}^{(6)}$. Furthermore, drinking plain water as part of an overall healthy diet can help weight management ${ }^{(7)}$.

$\uparrow$ The 2010 Dietary Guidelines for Americans defines sugar-sweetened beverages as 'Liquids that are sweetened with various forms of sugars that add calories. These beverages include, but are not limited to, soda, fruit ades and fruit drinks, and sports and energy drinks' (US Department of Agriculture \& US Department of Health and Human Services (2010) Dietary Guidelines for Americans, 2010, 7th ed., p. 95. Washington, DC: US Government Printing Office).
However, based on the 2005-2006 National Health and Nutrition Examination Survey (NHANES), the average plain water intake was about 1.06 litres/d and plain water intake was negatively associated with water intake from other beverages among adults aged $\geq 20$ years ${ }^{(8)}$.

A national poll conducted in the 1990s suggests that approximately one-third of Americans may mistrust their tap water $^{(9)}$. Mistrust of tap water may be even more common among Hispanics, leading them to avoid drinking tap water for themselves as well as for their children ${ }^{(10)}$. When people do not trust the quality of their tap water, they may be more likely to purchase and consume bottled beverages, including bottled water and SSB. For example, a perception that bottled water is safer than tap water was significantly associated with primarily bottled water use among parents ${ }^{(11)}$ and concerns about water quality were found to be more common among college students and adults who drank primarily bottled water ${ }^{(12,13)}$. Furthermore, in a focus group conducted in a rural region of 
California's central valley, Hispanic participants reported that they regularly consumed SSB and other beverages when bottled or filtered water was not available ${ }^{(14)}$. However, the relationship between trust of tap water and intake of SSB has not been quantitatively examined to date.

If mistrust of tap water is associated with increased intake of SSB, it would represent a modifiable community risk factor of considerable public health importance. Understanding the relationship between trust in tap water safety and plain water intake and SSB intake will help inform public health efforts to reduce SSB intake through promotion of drinking water. The present study examines whether reported mistrust of tap water is associated with intake of plain water and SSB among US adults and whether this association differs according to race/ethnicity.

\section{Experimental methods}

\section{Study population}

The present cross-sectional study was based on the HealthStyles Survey conducted in the autumn of 2010. The HealthStyles Survey is a national mail survey of US adults ( $\geq 18$ years) and is designed to assess a wide variety of respondents' health-related knowledge, attitudes, behaviours and conditions surrounding important public health issues, including dietary behaviours. The HealthStyles Survey is sent to the same individuals who complete and return the ConsumerStyles Survey, which is a consumer mail panel survey. The sampling and data collection are conducted by Synovate, Inc., a market research firm ${ }^{(15)}$. The Synovate, Inc. consumer mail panel consists of about 328000 potential respondents throughout the USA; this is a convenience sample based on their respondents on previous surveys over the years. Respondents are asked to join the mail panel through a recruitment survey and receive a small gift. The ConsumerStyles Survey is sent to a stratified random sample drawn from the potential respondents. Although this survey is administered to a convenience sample, it is stratified on region, household income, population density, age and household size to create a sample distribution similar to the national distribution. Low-income and minority groups are oversampled to have sufficient representation of these subgroups. In 2010, a total of 10328 people completed the ConsumerStyles Survey, yielding a response rate of $51.6 \%$. A total of 6255 HealthStyles Surveys were sent to a stratified random sample of households that returned the ConsumerStyles Survey. Responses were received from 4184 HealthStyles participants, yielding a response rate of $66.9 \%$. Compared with non-respondents, respondents included a somewhat higher percentage of older individuals, non-Hispanic whites and lower-income individuals. Participants in the HealthStyles Survey are assigned sample weights based upon sex, age, income, race and household size to match US Current Population Survey proportions $^{(16)}$ and to adjust for demographic differences that result from differences in sampling and response rates.
For the present cross-sectional analyses, a total of 397 participants with missing data were excluded; 100 for missing data on water perceptions; 132 for missing data on SSB or water intake; twenty-seven for missing data on education status; and 138 for missing data on physical activity status. This left a final analytic sample size of 3787 (90.5\% of all HealthStyles respondents).

The present analysis was exempt from the Centers for Disease Control and Prevention Institutional Review Board process because personal identifiers were not included in the data provided.

\section{Study variables}

\section{Perceptions of tap water}

Participants were asked to rate their agreement with the following statements: 'My local tap water is safe to drink' and 'Bottled water is safer than tap water'. Response choices available for both of these items were 'strongly disagree', 'somewhat disagree', 'neither agree nor disagree', 'somewhat agree' and 'strongly agree'. For bivariate analysis, three categories were created for each water perception variable: strongly/somewhat agree, neutral and strongly/ somewhat disagree. For logistic regression analysis, water perception variables were dichotomized. Participants were classified as having mistrust of tap water if they strongly or somewhat disagreed that their local tap water was safe to drink and as not having mistrust of tap water if they responded 'neither agree nor disagree', 'somewhat agree' and 'strongly agree'. Participants were classified as favouring bottled water if they strongly or somewhat agreed that bottled water was safer than tap water and as not favouring bottled water if they responded 'neither agree nor disagree', 'somewhat disagree' and 'strongly disagree'.

\section{Outcome variables for plain water and sugar-sweetened beverage intake}

Plain water intake was based upon the following question: 'On a typical day, how many times do you drink a glass or bottle of plain water? Count tap, water fountain, bottled, and unflavoured sparking water'. Response choices for water intake were 'none', ' 1 time per day', '2 times per day', ' 3 times per day', ' 4 times per day' or ' 5 times or more per day'. Participants were classified as having low intake of plain water if they drank $\leq 1$ time/d because it is likely these individuals derive little of their total water intake (water from all dietary sources) from plain water. SSB intake was based upon the following question: 'During the past $7 \mathrm{~d}$, how many times did you drink sodas, fruit drinks, sports or energy drinks or other sugar-sweetened drinks? Do not include $100 \%$ fruit juice, diet drinks or artificially sweetened drinks'. Response choices for SSB intake were 'none', ' 1 to 6 times per week', ' 1 time per day', ' 2 times per day', ' 3 times per day' or ' 4 or more times per day'. Participants were classified as daily SSB consumers if they responded that they consumed $\mathrm{SSB} \geq 1$ time/d. 


\section{Demographic variables}

Mutually exclusive categories were created for each covariate. Race/ethnicity was classified as non-Hispanic white, non-Hispanic black, Hispanic or non-Hispanic other. Participants were classified into three age categories: $18-34,35-54$ and $\geq 55$ years. Household income was classified into three categories: <\$US 25000, \$US 25000-59999 and $\geq \$$ US 60000 . Education was classified according to four categories: < high school, high school, some college and college graduate. Because individuals may be instructed to alter their dietary intake of SSB after diagnosis of diabetes, participants were classified as having diabetes based upon self-report of ever receiving treatment by a physician or health-care provider. Geographic regions of the country were classified according to the following nine categories: East North Central, West South Central, East South Central, Middle Atlantic, Mountain, New England, Pacific, South Atlantic and West North Central. Physical activity level was measured in adults using four questions that asked about the number of days and minutes per day of moderate physical activity and number of days and minutes per day of vigorous physical activity during a usual week. To categorize PA level, the total moderate intensity-equivalent minutes were calculated for each participant by summing the weekly minutes of moderate physical activity and two times the number of minutes of vigorous activity. Adults were classified as being either 'inactive' ( 0 weekly moderate intensity-equivalent minutes), 'insufficiently active' (1-149 weekly moderate intensity-equivalent minutes) or 'active' ( $\geq 150$ min weekly moderate intensity-equivalent minutes) ${ }^{(17)}$.

\section{Analysis}

The FREQ and LOGISTIC procedures with appropriate weight statements in SAS version $9 \cdot 2$ were used for analysis. Weighted frequencies of mistrust of tap water and favouring bottled water according to age, sex, race/ ethnicity, income, education, diabetes, physical activity level and region were compared using $\chi^{2}$ tests. Chi-square analysis and multivariable logistic regression was used to assess the association of mistrust of tap water and favouring bottled water with daily SSB intake and low plain water intake. Two separate models were fit for each outcome (daily SSB intake and low water intake). Both models included mistrust of tap water and favouring bottled water as the primary exposure variables and age, sex, income, education, race/ethnicity, regions of country, physical activity level and diabetes as covariates. Because previous studies have observed racial/ethnic differences in perceptions of tap water safety and because of qualitative evidence that tap water mistrust may be a unique risk factor for SSB intake among Hispanic populations ${ }^{(14)}$, interactions between race/ethnicity and mistrust of tap water and favouring bottled water were also assessed. Wald type-three analysis of effect tests with $\alpha$ level of 0.05 were used to assess the significance of interaction terms.
Separate $\chi^{2}$ analysis to assess the association of mistrust of tap water and favouring bottled water with daily SSB intake and low plain water intake was also performed for each racial/ethnic group. In supplementary analysis, the relationship between low plain water intake and SSB intake was also assessed in a multivariable model with the same covariables as used in the primary analysis.

To assess the appropriateness of the dichotomous classification of water perception variables, sensitivity analysis was performed by refitting the models with separate variables corresponding to neutral and negative water perceptions as compared with positive water perceptions. The resulting race/ethnicity-specific odds ratios corresponding to negative water perceptions were then compared with original estimates where the response category 'neither agree nor disagree' was included in the reference categories.

\section{Results}

\section{Water perceptions according to sociodemographic characteristics}

Overall, $13.0 \%$ of participants either somewhat or strongly disagreed that their local tap water was safe to drink and $26.4 \%$ of participants somewhat or strongly agreed that bottled water was safer than tap water. Both mistrust of tap water safety and favouring bottled water differed significantly by age, race/ethnicity, income and education (all $P<0 \cdot 0001$ ), with mistrust of tap water and favouring bottled water tending to be more prevalent among younger adults, non-whites and participants having lower income and less education (Table 1). Mistrust of tap water safety also tended to be more prevalent among those who were less active $(P=0 \cdot 004$; Table 1$)$. Favouring bottled water was more prevalent among persons with diabetes $(P=0 \cdot 0001)$. Both mistrust of tap water and favouring bottled water also differed significantly by region (both $P<0 \cdot 0001$ ), with mistrust of tap water ranging among regions from $4 \cdot 2 \%$ to $20 \cdot 1 \%$ and favouring bottled water ranging from $13 \cdot 4 \%$ to $35 \cdot 1 \%$ (Table 1 ). Mistrust of local tap water safety and favouring bottled water were also positively associated with each other such that $21.5 \%$ of those who favoured bottled water did not agree that their local tap water was safe, compared with $6.8 \%$ among those who disagreed bottled water was safer than tap water.

\section{Association of mistrust of tap water with sugar-sweetened beverage and plain water intake} Overall, 29.9\% of participants reported drinking at least one SSB daily. Results of the association of tap water perceptions with SSB and plain water intake are shown in Table 2. The percentage of participants consuming $\geq 1 \mathrm{SSB} / \mathrm{d}$ differed significantly according to mistrust of local tap water only among Hispanics $(P<0 \cdot 05)$. Specifically, $45 \cdot 6 \%$ of 
Table 1 Prevalence of tap water and bottled water safety perceptions according to characteristics of survey respondents: US adults aged $\geq 18$ years ( $n 3787), 2010$ HealthStyles Survey

\begin{tabular}{|c|c|c|c|c|c|c|c|c|}
\hline & \multicolumn{4}{|c|}{$\begin{array}{l}\text { Local tap water perceptions } \\
\text { 'My local tap water is safe to drink' }\end{array}$} & \multicolumn{4}{|c|}{$\begin{array}{l}\text { Bottled water perceptions } \\
\text { 'Bottled water is safer than tap water' }\end{array}$} \\
\hline & Disagree & Neutral & Agree & $P$ value & Agree & Neutral & Disagree & $P$ value \\
\hline$n$ & 456 & 679 & 2652 & - & 960 & 1365 & 1462 & - \\
\hline Weighted \%* & $13 \cdot 0$ & $19 \cdot 2$ & $67 \cdot 9$ & & $26 \cdot 4$ & $37 \cdot 4$ & $36 \cdot 2$ & \\
\hline \multicolumn{9}{|l|}{ Age (years) } \\
\hline $18-34$ & $14 \cdot 9$ & $23 \cdot 5$ & $61 \cdot 6$ & \multirow{3}{*}{$<0.0001$} & $29 \cdot 6$ & $40 \cdot 5$ & $29 \cdot 9$ & \multirow{3}{*}{$<0.0001$} \\
\hline $35-54$ & $15 \cdot 1$ & $19 \cdot 0$ & $65 \cdot 9$ & & $26 \cdot 9$ & $36 \cdot 5$ & $36 \cdot 6$ & \\
\hline$\geq 55$ & $8 \cdot 3$ & $15 \cdot 1$ & $76 \cdot 6$ & & $22 \cdot 6$ & $35 \cdot 5$ & $41 \cdot 9$ & \\
\hline \multicolumn{9}{|l|}{ Sex } \\
\hline Male & $12 \cdot 3$ & $19 \cdot 9$ & $67 \cdot 1$ & \multirow[t]{2}{*}{$0 \cdot 5$} & $27 \cdot 0$ & $37 \cdot 3$ & $35 \cdot 8$ & \multirow[t]{2}{*}{$0 \cdot 8$} \\
\hline Female & $13 \cdot 5$ & $19 \cdot 4$ & $67 \cdot 1$ & & $26 \cdot 0$ & $37 \cdot 6$ & $36 \cdot 5$ & \\
\hline \multicolumn{9}{|l|}{ Race/ethnicity } \\
\hline Non-Hispanic white & $10 \cdot 8$ & $16 \cdot 9$ & $72 \cdot 4$ & \multirow[t]{4}{*}{$<0.0001$} & $21 \cdot 8$ & $38 \cdot 0$ & $40 \cdot 2$ & \multirow[t]{4}{*}{$<0.0001$} \\
\hline Non-Hispanic black & $19 \cdot 9$ & $24 \cdot 5$ & $55 \cdot 6$ & & $40 \cdot 0$ & $34 \cdot 6$ & $25 \cdot 4$ & \\
\hline Hispanic & $16 \cdot 0$ & 24.9 & $59 \cdot 2$ & & $34 \cdot 1$ & $38 \cdot 0$ & $28 \cdot 0$ & \\
\hline Non-Hispanic other & $18 \cdot 0$ & $22 \cdot 4$ & $59 \cdot \overline{6}$ & & $36 \cdot 6$ & $34 \cdot 6$ & $28 \cdot 8$ & \\
\hline \multicolumn{9}{|l|}{ Income } \\
\hline$<\$ U S 25000$ & $15 \cdot 3$ & $25 \cdot 4$ & $59 \cdot 4$ & \multirow[t]{3}{*}{$<0.0001$} & $34 \cdot 3$ & $38 \cdot 6$ & $27 \cdot 1$ & \multirow[t]{3}{*}{$<0.0001$} \\
\hline \$US 25000-59999 & $14 \cdot 1$ & $17 \cdot 1$ & $68 \cdot 8$ & & $22 \cdot 9$ & $41 \cdot 3$ & $35 \cdot 9$ & \\
\hline$\geq$ \$US 60000 & $10 \cdot 8$ & $17 \cdot 4$ & $71 \cdot 8$ & & $24 \cdot 8$ & $33 \cdot 9$ & $41 \cdot 3$ & \\
\hline \multicolumn{9}{|l|}{ Education } \\
\hline$<$ High school & $17 \cdot 0$ & $19 \cdot 7$ & $63 \cdot 3$ & \multirow[t]{4}{*}{$<0.0001$} & $40 \cdot 0$ & $28 \cdot 6$ & $31 \cdot 4$ & \multirow[t]{4}{*}{$<0 \cdot 0001$} \\
\hline High school & $15 \cdot 1$ & $19 \cdot 4$ & $65 \cdot 5$ & & $27 \cdot 5$ & $41 \cdot 7$ & $30 \cdot 8$ & \\
\hline Some college & $16 \cdot 1$ & $21 \cdot 9$ & $62 \cdot 1$ & & $29 \cdot 5$ & $39 \cdot 4$ & $31 \cdot 1$ & \\
\hline College graduate & $7 \cdot 1$ & $15 \cdot 4$ & $77 \cdot 5$ & & $19 \cdot 9$ & $33 \cdot 4$ & $46 \cdot 7$ & \\
\hline \multicolumn{9}{|l|}{ Self-reported diabetes } \\
\hline Diabetes & $11 \cdot 2$ & $20 \cdot 0$ & $66 \cdot 8$ & \multirow[t]{2}{*}{0.5} & $33 \cdot 3$ & $37 \cdot 9$ & $28 \cdot 8$ & \multirow[t]{2}{*}{0.0001} \\
\hline No diabetes & $13 \cdot 2$ & $19 \cdot 1$ & $67 \cdot 8$ & & $25 \cdot 4$ & $37 \cdot 4$ & $37 \cdot 2$ & \\
\hline \multicolumn{9}{|l|}{ Physical activity level } \\
\hline Inactive & $16 \cdot 5$ & $21 \cdot 1$ & $62 \cdot 5$ & 0.004 & $28 \cdot 2$ & $36 \cdot 6$ & $35 \cdot 2$ & 0.3 \\
\hline Insufficiently active & $13 \cdot 3$ & $18 \cdot 3$ & $68 \cdot 4$ & & $28 \cdot 2$ & $35 \cdot 7$ & $36 \cdot 1$ & \\
\hline Active & $11 \cdot 6$ & $18 \cdot 9$ & $69 \cdot 5$ & & $25 \cdot 1$ & $38 \cdot 4$ & $36 \cdot 5$ & \\
\hline Region & & & & & & & & \\
\hline New England & $4 \cdot 2$ & $18 \cdot 5$ & $77 \cdot 4$ & $<0.0001$ & $35 \cdot 1$ & $31 \cdot 5$ & $33 \cdot 4$ & $<0.0001$ \\
\hline Middle Atlantic & $15 \cdot \overline{5}$ & $20 \cdot 3$ & $64 \cdot 2$ & & $22 \cdot 9$ & $40 \cdot 6$ & $36 \cdot 5$ & \\
\hline South Atlantic & $11 \cdot 6$ & $21 \cdot 6$ & $66 \cdot 8$ & & $27 \cdot 1$ & $35 \cdot 6$ & $37 \cdot 4$ & \\
\hline East North Central & $14 \cdot 6$ & $14 \cdot 5$ & $70 \cdot 9$ & & $27 \cdot 2$ & $38 \cdot 5$ & $34 \cdot 2$ & \\
\hline East South Central & $8 \cdot 1$ & $23 \cdot 2$ & $68 \cdot 7$ & & $25 \cdot 0$ & $32 \cdot 6$ & $42 \cdot \overline{3}$ & \\
\hline West North Central & $5 \cdot 6$ & $17 \cdot 1$ & $77 \cdot 3$ & & $13 \cdot 4$ & $48 \cdot 7$ & $37 \cdot 9$ & \\
\hline West South Central & $20 \cdot 1$ & $20 \cdot 9$ & $59 \cdot 0$ & & $34 \cdot 6$ & $33 \cdot 0$ & $32 \cdot 4$ & \\
\hline Mountain & $13 \cdot 7$ & $15 \cdot 3$ & $71 \cdot 0$ & & $24 \cdot 1$ & $36 \cdot 6$ & $39 \cdot 2$ & \\
\hline Pacific & $14 \cdot 3$ & $20 \cdot 2$ & $65 \cdot 6$ & & $30 \cdot 5$ & $35 \cdot 1$ & $34 \cdot 4$ & \\
\hline Agree bottled water is safer than tap & $21 \cdot 5$ & $31 \cdot 2$ & $47 \cdot 4$ & $<0.0001$ & - & - & - & - \\
\hline Neutral bottled water is safer than tap & $12 \cdot 9$ & $20 \cdot 8$ & $66 \cdot 3$ & & - & - & - & - \\
\hline Disagree bottled water is safer than tap & $6 \cdot 8$ & $8 \cdot 7$ & $84 \cdot 5$ & & - & - & - & - \\
\hline Disagree home tap water is safe & - & - & - & - & $43 \cdot 8$ & $37 \cdot 2$ & $19 \cdot 0$ & $<0.0001$ \\
\hline Neutral home tap water is safe & - & - & - & - & $42 \cdot 9$ & $40 \cdot 6$ & $16 \cdot 5$ & \\
\hline Agree home tap water is safe & - & & - & - & $18 \cdot 5$ & $36 \cdot 6$ & $45 \cdot 0$ & \\
\hline
\end{tabular}

${ }^{*}$ All percentages weighted based upon sex, age, income, race and household size; because of rounding, weighted percentages may not add up to $100 \%$.

Hispanics who mistrusted the safety of their local tap water consumed $\geq 1 \mathrm{SSB} / \mathrm{d}$ compared with $28.8 \%$ of Hispanics who believed their local tap water was safe or were neutral regarding the safety. When the data were fitted to a multivariable model, the relationship between mistrust of local tap water with daily SSB intake was significantly modified by race/ethnicity $(P=0.007$ for tap water $\times$ race interaction). The adjusted odds of consuming $\geq 1 \mathrm{SSB} / \mathrm{d}$ among Hispanics who mistrusted their local tap water was twice that of Hispanics who did not $(\mathrm{OR}=2 \cdot 0)$ and mistrust of local tap water was negatively associated with SSB intake among those of non-Hispanic other races.
Overall, $18.5 \%$ of participants reported drinking $\leq 1$ glass or bottle of plain water daily. Hispanics, blacks and those of non-Hispanic other races who disagreed that their local tap water was safe to drink were all significantly more likely to drink $\leq 1$ glass or bottle plain water/d $(22 \cdot 8 \% v \cdot 12 \cdot 3 \%$ among Hispanics; $45 \cdot 3 \% v .15 \cdot 1 \%$ among blacks; $52.5 \% v$. $17.5 \%$ among other races; all $P<0 \cdot 05$ ). This relationship was not seen among non-Hispanic whites. When the data were fitted to a multivariable model, the relationship between mistrust of local tap water and low water intake was significantly modified by race/ethnicity $(P<0 \cdot 0001$ for interaction). The adjusted odds of low plain water intake 
was approximately twice as high $(\mathrm{OR}=1 \cdot 9)$ among Hispanics who disagreed their local tap water was safe and over four times as high among blacks $(\mathrm{OR}=4 \cdot 2)$ and those of non-Hispanic other races $(\mathrm{OR}=4 \cdot 7)$ who disagreed their local tap water was safe.

\section{Association of bottled water perceptions with sugar-sweetened beverage and plain water intake}

Results of the association of bottled water perceptions with SSB and plain water intake are shown in Table 2. The percentage of participants who consumed $\geq 1 \mathrm{SSB} / \mathrm{d}$ was significantly greater among those of non-Hispanic other races who believed bottled water was safer than tap water $(46 \cdot 9 \% v \cdot 30 \cdot 4 \%, P=0 \cdot 01)$ but lower among blacks who believed bottled water was safer than tap water (31.5\% v. 43.1\%,P=0.02). These relationships remained significant after adjustment and there was significant effect modification of favouring bottled water on SSB intake by race/ethnicity $(P=0 \cdot 002)$. The belief that bottled water is safer than tap water was not significantly associated with low intake of plain water and this relationship was not modified significantly by race/ethnicity $(P=0 \cdot 2$ for interaction).

In supplemental analysis, low intake of plain water was significantly associated with consumption of $\geq 1 \mathrm{SSB} / \mathrm{d}$ (adjusted $\mathrm{OR}=1 \cdot 5 ; 95 \% \mathrm{CI} 1 \cdot 2,1 \cdot 8$; data not shown). In sensitivity analysis of the classification of water perceptions, the directions of race-specific odds ratios for SSB intake and low plain water intake were unchanged and the magnitudes of odds ratios were similar when neutral responses for water perception questions were removed from reference categories (results not shown).

\section{Discussion}

The results of the present study suggest that one in eight Americans disagrees that their local tap water is safe to

Table 2 Associations of perceptions of tap and bottled water safety with daily intake of sugar-sweetened beverages (SSB) and low intake of plain drinking water*: US adults aged $\geq 18$ years ( $n 3787$ ), 2010 HealthStyles Survey

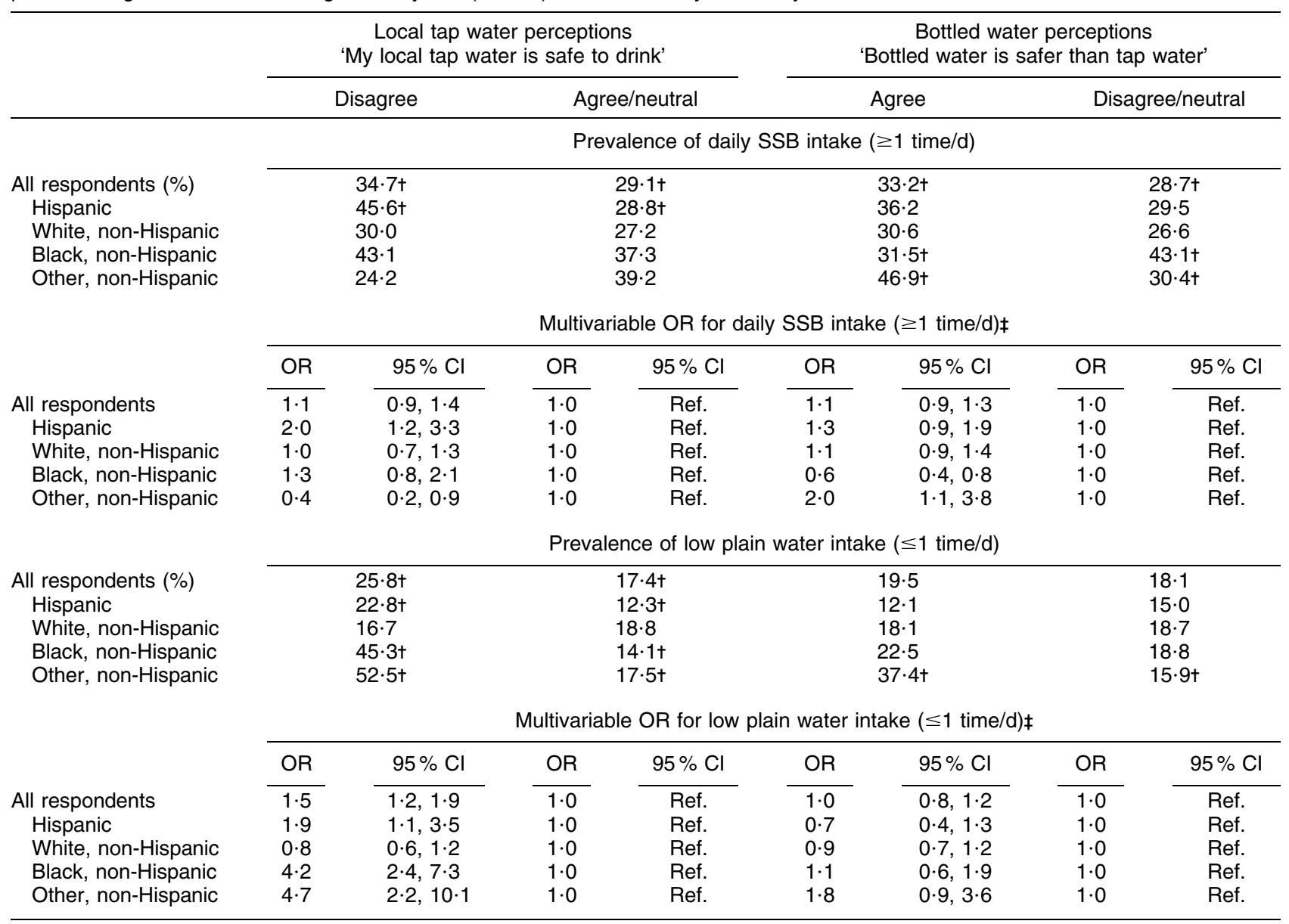

Ref, reference category.

${ }^{*}$ All interactions between race and tap water and between race and bottled water were significant except for interaction between race and bottled water perception on low water intake.

$+\chi^{2} P<0.05$ for difference in proportions in SSB or water intake according to water perception.

fOR where the $\mathrm{Cl}$ does not include 1.0 denote significant findings based on the $95 \% \mathrm{Cl}$. OR are adjusted for age, sex, income, education, race/ethnicity, regions of country, physical activity level and diabetes. OR for 'all respondents' are derived from adjusted models that do not include interaction terms. 
drink and one in four believes that bottled water is safer than tap water. Both disagreement with the safety of local tap water and the belief that bottled water is safer than tap water varied by region of the country and were more common among younger adults, lower socio-economic status populations and non-white racial/ethnic groups. The study also found significant racial/ethnic differences in how water safety perceptions relate with consumption of plain water and SSB. Specifically, disagreement with the safety of local tap water was associated with low intake of plain water among all non-whites including Hispanics, blacks and those of non-Hispanic other races, but was associated with greater probability of SSB intake only among Hispanics. However, the belief that bottled water is safer than tap water was not associated with low plain water intake and was associated with greater probability of SSB intake only among those of non-Hispanic other racial/ethnic groups.

Previous studies have suggested that concerns regarding tap water safety vary significantly by region ${ }^{(12)}$ and are more common among young adults ${ }^{(12)}$ and minority populations ${ }^{(11,18,19)}$. In particular, Hobson et al. found that among those surveyed, $42 \%$ of low-income Latinos served by a public health clinic in Salt Lake city avoided tap water because they believed it caused illness compared with only $12 \%$ of non-Latinos served by the same clinic $^{(18)}$. Likewise, Gorelick et al. found that perceptions of bottled water being cleaner and safer than tap water were two to three times more common among blacks and Latinos as compared with non-Hispanic whites surveyed at a paediatric hospital in Wisconsin ${ }^{(11)}$. Finally, a survey of predominantly black adolescents and caregivers at paediatric practices in Philadelphia found that study participants rated the taste, clarity, purity and safety of bottled water higher than tap water ${ }^{(19)}$. According to the US Environmental Protection Agency, approximately $96 \%$ of Americans are served by community water systems ${ }^{(20)}$. Of the population served by these systems, fewer than $10 \%$ are served by systems that report health-based violations in any given year ${ }^{(20)}$. Unfortunately, although there are several case reports of water infrastructure disparities, there is a paucity of data regarding systematic disparities in drinking water access and quality ${ }^{(21)}$. To our knowledge, the present study is the first one to examine the relationship between perceptions of tap water safety and intake of SSB and plain water. However, there is qualitative evidence to suggest that water safety concerns may lead Hispanics to consume more SSB when filtered or bottled water is not available ${ }^{(14)}$ and previous studies have shown that water quality concerns are associated with bottled water use ${ }^{(12,13)}$. Regarding the association between water intake and SSB intake, previous research using NHANES data has shown that intake of plain water, as measured by in-person interview using measurement guides, is inversely correlated with intake of other beverages and added sugar intake ${ }^{(8)}$ but did not find significant differences in plain water intake according to racial/ethnic group ${ }^{(8)}$.

There are several limitations to the present crosssectional study. First, the findings may not be generalizable nationally because of selection bias associated with the use of a convenience sample from a mail panel survey with a relatively low response rate. However, a previous study has shown that certain items from HealthStyles (e.g. health conditions, attitudes and behaviours) are comparable to the Behavioral Risk Factor Surveillance System, which uses a probability sampling technique ${ }^{(22)}$. Second, the HealthStyles data are self-reported and the SSB and water intake data used in the present study are based upon single question survey items, which may result in misclassification. Furthermore, measurement of water intake remains a challenge for all researchers and there is a lack of validated instruments for this purpose $^{(23)}$. We also did not have specific data on intake of bottled water or artificially sweetened beverages, which would have been useful in further exploring how tap water perceptions impact beverage choices. Third, because of the somewhat limited number of categories of race/ethnicity, it is also difficult to interpret associations observed with individuals whose ethnicity was classified as non-Hispanic other. Similarly, it was not possible to ascertain if racial/ethnic differences in associations observed were further modified by country of birth or acculturation because this information was not collected in the survey. Finally, our research highlights the importance of how perceptions of tap water are ascertained and classified. Specifically, large differences were observed in the prevalence of local tap water safety mistrust (13\% overall) and prevalence of the belief that bottled water was safer than tap water ( $26 \%$ overall), as well as in the associations of these variables with SSB and water intake. Clearly, methodological research on the measurement of tap water safety perceptions is warranted.

\section{Conclusions}

Our study suggests that mistrust of local tap water safety is common and varies by age, income, education, region and race/ethnicity. Mistrust of tap water safety could be a risk factor for SSB intake among Hispanics and may result in low intake of plain water among many minority populations. Given the relatively common prevalence of this belief among Hispanics suggested by the present and other studies ${ }^{(10,11)}$, concerns regarding tap water safety may be an important determinant of SSB intake among Hispanics. Public health efforts to decrease intake of SSB through promotion of plain drinking water should recognize the role of perceptions regarding tap water safety on water and SSB intake among minority populations. 


\section{Acknowledgements}

Sources of funding: This research received no specific grant from any funding agency in the public, commercial or not-for-profit sector. Conflicts of interest: None of the authors have conflicts of interest to declare. Authors' contributions: S.J.O. and S.P. contributed to study design, analysis and manuscript preparation. J.R.S. and B.S. contributed to manuscript preparation.

\section{References}

1. Ogden CL, Kit BK, Carroll MD et al. (2011) Sugar Drink Consumption in the United States, 2005-2008. NCHS Data Brief no. 71. Hyattsville, MD: National Center for Health Statistics.

2. Ebbeling CB, Feldman HA, Osganian SK et al. (2006) Effects of decreasing sugar-sweetened beverage consumption on body weight in adolescents: a randomized, controlled pilot study. Pediatrics 117, 673-680.

3. Malik VS, Schulze MB \& Hu FB (2006) Intake of sugarsweetened beverages and weight gain: a systematic review. Am J Clin Nutr 84, 274-288.

4. Shi Z, Taylor AW, Wittert G et al. (2010) Soft drink consumption and mental health problems among adults in Australia. Public Health Nutr 13, 1073-1079.

5. Malik VS, Popkin BM, Bray GA et al. (2010) Sugar-sweetened beverages and risk of metabolic syndrome and type 2 diabetes: a meta-analysis. Diabetes Care 33, 2477-2483.

6. Institute of Medicine (2009) Local Government Actions to Prevent Childhood Obesity. Washington, DC: National Academies Press.

7. Daniels M \& Popkin B (2010) Impact of water intake on energy intake and weight status: a systematic review. Nutr Rev 68, 505-521.

8. Kant AK, Graubard BI \& Atchison EA (2009) Intakes of plain water, moisture in foods and beverages, and total water in the adult US population - nutritional, meal pattern, and body weight correlates: National Health and Nutrition Examination Surveys 1999-2006. Am J Clin Nutr 90, 655-663.

9. Cable News Network, USA Today (1998) Gallup/CNN/USA Today Poll, June 1998. http://www.kff.org/kaiserpolls/ healthpoll_question.cfm?qid $=343868 \& \mathrm{recID}=31 \& \mathrm{pid}=4 \&$ $\mathrm{ccid}=0 \&$ recs $=62 \&$ iprecs $=155 \& \mathrm{~s}=$ drinking $\% 20$ and $\% 20$ water $\& \mathrm{t}=\& \mathrm{tid}=\& \mathrm{sdate}=\& \mathrm{edate}=\& \mathrm{org}=\# \_$topdoc_ $\quad($ accessed March 2011).
10. Hobson W, Knochel M, Byington C et al. (2007) Bottled, filtered, and tap water use in Latino and non-Latino children. Arch Pediatr Adolesc Med 161, 457-461.

11. Gorelick MH, Gould L, Nimmer M et al. (2011) Perceptions about water and increased use of bottled water in minority children. Arch Pediatr Adolesc Med 165, 928-932.

12. Hu Z, Morton LW \& Mahler RL (2011) Bottled water: United States consumers and their perceptions of water quality. Int J Environ Res Public Health 8, 565-578.

13. Saylor A, Prokopy LS \& Amberg S (2011) What's wrong with the tap? Examining perceptions of tap water and bottled water at Purdue University. Environ Manage 48, 588-601.

14. Scherzer T, Barker JC, Pollick $\mathrm{H}$ et al. (2010) Water consumption beliefs and practices in a rural Latino community: implications for fluoridation. J Public Health Dent 70, 337-343.

15. Porter Novelli (2009) HealthStyles 2009: Methods. Washington, DC: Porter Novelli.

16. US Census Bureau (2012) Current Population Survey (CPS). http://www.census.gov/cps/ (accessed April 2011).

17. US Department of Health and Human Services (2008) 2008 Physical Activity Guidelines for Americans. Atlanta, GA: DHHS.

18. Hobson WL, Knochel ML, Byington CL et al. (2007) Bottled, filtered, and tap water use in Latino and non-Latino children. Arch Pediatr Adolesc Med 161, 457-461.

19. Huerta-Saenz L, Irigoyen M, Benavides J et al. (2012) Tap or bottled water: drinking preferences among urban minority children and adolescents. $J$ Community Health 37, 54-58.

20. US Environmental Protection Agency (2010) Population Served by Community Water Systems with No Reported Violations of Health-Based Standards. http://cfpub.epa. gov/eroe/index.cfm?fuseaction $=$ detail.viewPDF $\& \mathrm{ch}=47$ \&IShowInd $=0$ \&subtop $=203 \& l v=$ list.listByChapter $\& \mathrm{r}=216626$ (accessed June 2012).

21. VanDerslice J (2011) Drinking water infrastructure and environmental disparities: evidence and methodological considerations. Am J Public Health 101, Suppl. 1, S109-S114.

22. Pollard WE (2002) Use of a consumer panel survey for public health communication planning: an evaluation of survey results. In Proceedings of the American Statistical Association Joint Statistical Meeting. Section on Health Policy Statistics, New York, 11-15 August 2002, pp. 2120-2124.

23. Popkin B, D'Anci K \& Rosenberg I (2010) Water, hydration, and health. Nutr Rev 68, 439-458. 